\title{
Evaluation of Enset Fabric Reinforced Green Composite as Sound Absorber Structure
}

\author{
Alhayat Getu TEMESGEN ${ }^{1}$ (D) 0000-0001-7841-2281 \\ Recep EREN ${ }^{1.2}$ (D) 0000-0001-9389-0281 \\ Yakup AYKUT ${ }^{1.2}$ (D) 0000-0002-5263-1985 \\ Fatih SÜVARI ${ }^{1.2}$ (iD) 0000-0001-5708-7993
}

${ }^{1}$ Bursa Uludag University, Graduate School of Natural and Applied Sciences, Department of Textile Engineering, Bursa, Turkey ${ }^{2}$ Bursa Uludag University, Engineering Faculty, Department of Textile Engineering, Bursa, Turkey

Corresponding Author: Recep EREN, erecep@uludag.edu.tr

\begin{abstract}
Noise is a problem that should be reduced in a variety of places. Fibrous structures are some of the most commonly used materials for sound absorption applications. Enset fibers have a limited use in technical textile applications especially in packaging sector and are mostly left as an agro waste materials. The aim of this research work was to investigate the acoustic property of this new alternative natural fiber (fabric) and its green composite material. The sound absorption performance of enset fabric and its green composite was determined with impedance tube method. The porosity and void structure of enset fibers were studied by scanning electron microscope (SEM) for analysis of enset fabric and enset fabric reinforced composite sound dissipation mechanism. The sound absorption coefficient of enset fabric could only reach to 0.5 level with 5 layers of enset fabric after $3500 \mathrm{~Hz}$ frequency. Composite structures with increasing number of fabric layers decreased sound absorption frequency interval. With 5 layers composite ( 5 fabric layers in the composite), a sound absorption coefficient remained over 0.5 at a large frequency interval between 2830 and $6000 \mathrm{~Hz}$ while it was reaching to 0.9 at around $2500 \mathrm{~Hz}$ frequency. Increasing the ratio of bio resin to enset fabric caused the sound absorption behavior of composite material tend to shift from higher to medium frequency regions.
\end{abstract}

\author{
ARTICLE HISTORY \\ Received: 12.02 .2020 \\ Accepted: 03.06.2021
}

\section{KEYWORDS}

Acoustic Property, Air Permeability, Enset Fabric, Green Composite, Noise, Porosity

\section{INTRODUCTION}

Noise pollution is one of the most series problems in most urban and industrial areas [1]. It is the result of an unwanted sound which disturbs comfort and human health [1, 2]. Materials used for noise reduction are categorized as sound absorbing as well as sound insulating materials [1- 3]. Most commonly used sound absorbing materials have been manufactured from petrochemical products [3]. Use of synthetic materials may cause environmental problems for the society [4]. Moreover, synthetic fibers used for sound absorption have high cost of manufacturing and nonrenewability [5]. Due to the environmental regulations, safety issues and concerns for human health, the researchers and manufacturers have been pushed to find out new alternative materials from nature replacing synthetic ones [6]. Additionally, rapidly increasing cost of petroleum based polymers are encouraging manufacturers to focus on the fabrication of green products to reduce high noise level
[6-12]. Their light weight, abundantly availability, nontoxic and ecofriendly properties make natural fiber reinforced composite materials more popular and attractive in acoustic industry [6, 13-15]. However, because of different types of adhesion interfacial, high moisture absorption and poor antifungal properties, the natural fibers and their composites are not still effectively utilized in place of petrochemical based structures $[6,7,16]$. Researchers have tried to overcome the limitations of natural fibers by treating them before composite manufacturing $[6,7,16]$. Commonly used industrial sound absorbing materials are mostly manufactured from mineral fibers, foam and their composites. However, these fibers and their composites are heavy, expensive, high energy consuming and brittle $[8,9$, 17].

Air permeability is one of the most desirable properties in the textile products, especially in clothing, parachute and air bag sectors $[10,18]$. It is the ability of porous materials to

To cite this article: Temesgen AG, Eren R, Aykut Y, Süvari F. 2021. Evaluationof Enset Fabric Reinforced Green

Composite as Sound Absorber Structure. Tekstil ve Konfeksiyon, 31(2), 73-81. 
transmit the air $[10,18]$. This property of textile product is affected by several factors such as type of yarn, twist level, thickness, porosity and fabric construction [10, 20]. Likewise, the acoustic behavior of composite materials is influenced by fiber type, thickness, air flow resistance and porosity of the used structure $[11,19,20]$.

Materials produced from glass fiber have been commonly used as sound absorbers [11, 21]. Glass fiber is brittle and heavy $(2.5 \mathrm{~g} / \mathrm{cm} 3)$ mineral fiber [11, 21]. Recently noise controlling materials have been attempted to be manufactured from natural fibers like jute, sisal, banana and flax fibers [11, 22]. Natural fiber reinforced composite materials have a potential to substitute the commonly used synthetic fiber reinforced noise control structures with manageable mechanical properties [11, 22-24]. Due to the development of technology, agricultural activities have been increased. Because of this, agro waste materials have also increased and caused a serious problem for their disposal [4, $11,22-24]$. Open burning of agro waste materials plays a negative role for global warming [4, 22, 24].

Enset is one of the most drought tolerant and new alternative textile fibers grown in Ethiopia. Enset is mostly un-utilized agro waste fibers obtained from the pseudo stem (bast) and mid ribs of enset plant, which morphologically resemble to banana fiber [25]. Its abundantly availability, low cost, light weight and good specific strength are the major advantages for potential application in technical textiles, especially lightweight materials used in green composites as well as in packaging industry [25, 26]. It has an average equivalent diameter of $194-206 \mu \mathrm{m}, 1.2 \mathrm{~g} / \mathrm{cm}^{3}$ of density and a length of 0.5 to $4.5 \mathrm{~m}[25,26]$. The structure of enset fiber is composed of a lot of porous and void areas $[25,26]$. Due to its porosity and void structure, air can easily circulate through enset fiber fabricated materials and it affects the air permeability and sound absorption properties of the fabrics as well as its composites [25 -27]. Yet, there is no significant data found in the literature about the acoustic properties of enset fabrics and enset fiber reinforced composite materials. Its bio degradability, effectively nonutilization, low density, good mechanical strength, no negative health effect and hallow like morphology are the driving factors to study the fiber as a new alternative sound absorbing material for the acoustic applications.

In this research work, green composite materials were manufactured with hand lay technique by using enset fabric as reinforcing material and plant secrete gums of acacia and frankincense as a bio resin. The composite structure was entirely manufactured from natural resources. Enset fabric and enset fabric reinforced composite material's air permeability and sound absorption properties were studied. Also the effect of porosity and thickness on air permeability and sound absorption behavior was analyzed. Moreover, the influence of the ratio of resin to enset fabric on sound absorption and air permeability was studied.

\section{MATERIAL AND METHOD}

\subsection{Material}

Enset fibers are extracted from mid ribs and bast of the plant with mechanically decortication and retting of the leaves as well as the bast by continuously scratching by hand followed by washing, cleaning and fiber separation. Finally, enset yarns are produced on jute spinning machines. Enset fabric for the experimental work was bought from G7 packaging industry company in Ethiopia. It has plain woven structure (warp is 74 Tex and weft is 67 Tex). Acacia (under Acacia Tortilis family) and frankincense (under Boswellia family) natural gums were collected from trees, cleaned and prepared as bio-matrix. Enset fabric was used as reinforcing material for the manufacturing of green composite structure. Acacia and frankincense bio resin was used as matrix. EVO 40Scanning Electron Microscope (SEM) was used for analyzing enset fiber morphology. BSWA-SW260 sound absorption tester and SDLATLAS-MO21A air permeability tester were used for measuring the sound absorption coefficient and air permeability properties of enset fabric and its composite respectively. Table 1 shows testing materials and their specifications for sound absorption measurements. Similarly, Table 2 presents materials and their specifications used in air permeability tests.

Table 1. Sound Absorption Test Specification

\begin{tabular}{l|c|c|c|c}
\hline Sample Type & $\begin{array}{c}\text { No. of fabric layer } \\
\text { (Reinforcement) }\end{array}$ & Thickness (mm) & Sample Diameter (mm) & Weight (g) \\
\hline Enset Fabric & 1 & 2.0 & 30.0 & 0.43 \\
Single Layer Composite & 1 & 2.5 & 30.0 & 1.05 \\
Double Layer Composite & 2 & 3.5 & 30.0 & 1.88 \\
\hline
\end{tabular}

Table 2. Air Permeability Test Specification

\begin{tabular}{l|c|c|c|c}
\hline Sample Type & $\begin{array}{c}\text { No. of fabric layer } \\
\text { (Reinforcement) }\end{array}$ & $\begin{array}{c}\text { Thickness } \\
(\mathrm{mm})\end{array}$ & $\begin{array}{c}\text { Sample Area } \\
\left(\mathrm{mm}^{2}\right)\end{array}$ & $\begin{array}{c}\text { Weight } \\
(\mathrm{g})\end{array}$ \\
\hline Enset Fabric & 1 & 2.0 & 500.0 & 0.8 \\
Single Layer Composite & 1 & 2.5 & 500.0 & 2.19 \\
Double Layer Composite & 2 & 3.5 & 500.0 & 3.45 \\
\hline
\end{tabular}




\subsection{Method}

Green composite structures were manufactured by using acacia-frankincense bio resin and enset fabric with resin to enset fabric weight ratio of 80:20 wt. \% and 70:30 wt. \%. Hand lay-up composite manufacturing technique was used to manufacture the composite. Then the samples were dried in oven for one hour period (with Rapid oven) at a temperature of $115 \pm 2{ }^{0} \mathrm{C}$ before cooling at room temperature. The samples were prepared according to the TS-391-ISO 9237 and ASTM E1050 standards for air permeability and sound absorption tests respectively (see Figure $1 \mathrm{a}-\mathrm{c})$. The air permeability and sound absorption measurements were carried out from 5 different samples.

Sound absorption: The sound absorption coefficient of enset fabric and its reinforced composite was measured by using Impedance Tube Method (ASTM E1050). Enset fabric and its composite samples were prepared with a diameter of $30 \mathrm{~mm}$ and fixed to the instrument as seen in Figure 2a. The sound wave was released and propagated from the load speaker to strike the enset samples at the other side of the equipment and the test result was recorded. The measurements were done at the frequency interval of 1000-6000 Hz.

Air permeability: SDLATLAS-MO21A air permeability tester was used for measuring the air permeability of enset fabrics and their composites. According to the test standard, the measurements were conducted from $500.0 \mathrm{~mm} 2$ area of enset fabrics and their composites. Firstly, the air permeability tester was calibrated and then the air pressure was set to $200 \mathrm{~Pa}$. The samples were loaded and the tests were conducted by pressing the pressure arm (see Figure $2 b)$. The test results were recorded after the green light turned on.
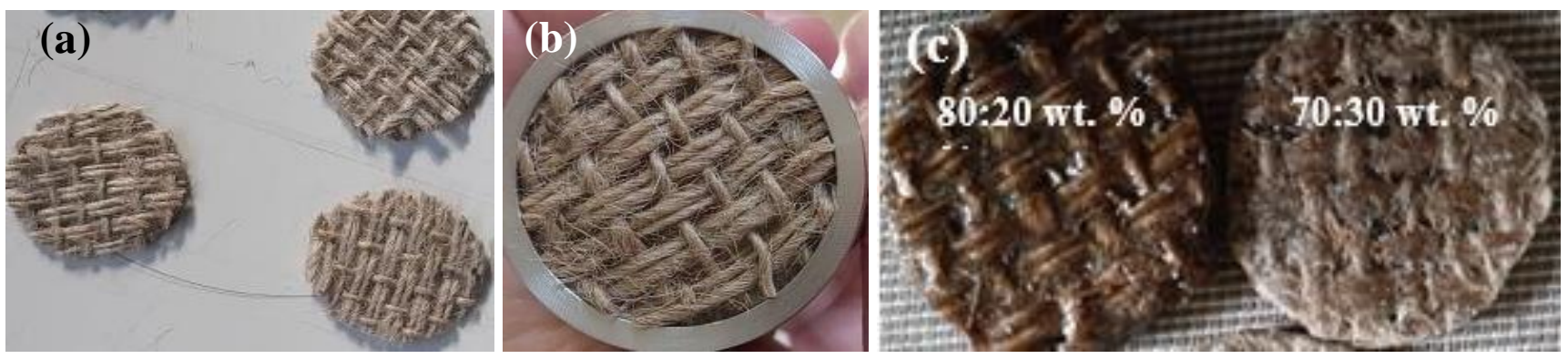

Figure 1. (a) Enset Fabric sample (b) Test Sample Holder (C) Green Composite Samples for Air Permeability and Sound Absorption measurements.
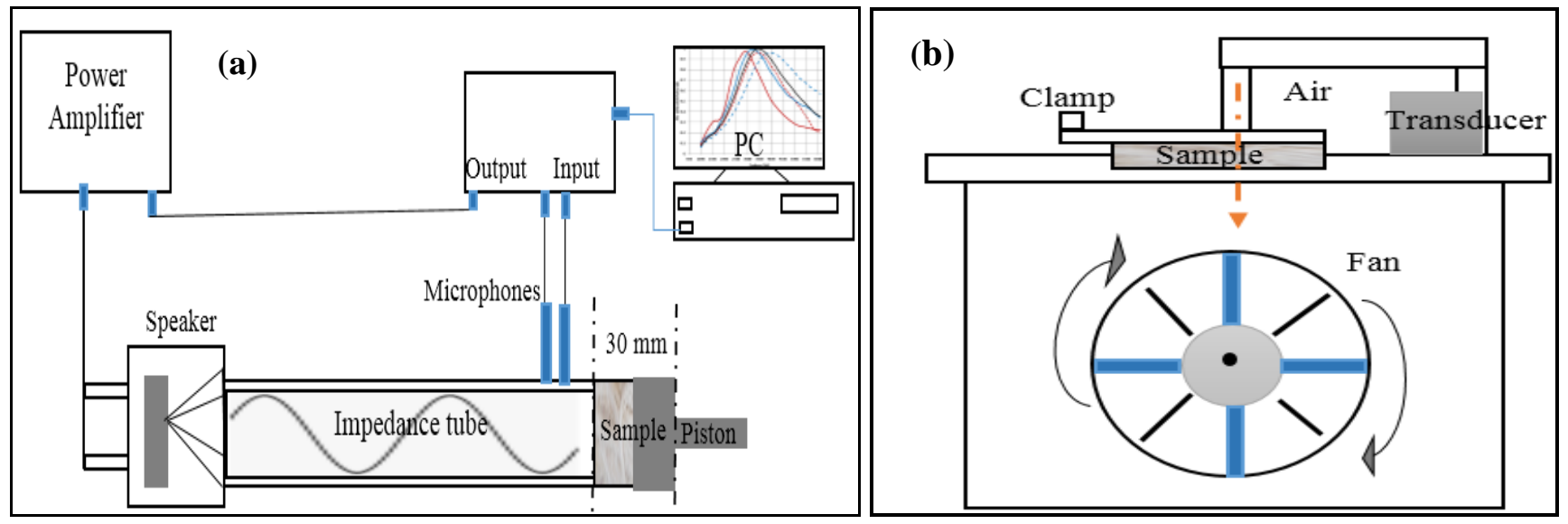

Figure 2. (a) Impedance Tube Sound Absorption Tester (b) Air Permeability Tester.

\section{RESULTS AND DISCUSSION}

In the literature, most of the studies have focused on the effect of porosity and void structure on sound absorption as well as sound insulation characteristics of textile fibers at higher frequencies [27]. In this study, the sound absorption properties of enset fabrics and their reinforced bio composite structures at medium and higher frequencies were explained in detail. 


\subsection{Morphological Analysis of enset fiber for sound absorption}

As seen in Figure $3 a$ and $3 b$, the enset fibers have a lot of porous and void structures in the longitudinal direction of the fiber axis. The porosities and voids present on the fiber structures could have a significant advantage in the sound absorption applications by dissipating sound energy (wave) through air molecules entrapped in the wall of the fibers (see in Figure 3c). The friction and collapsing of air molecules in the wall of the enset fiber structure would result sound energy loss in the form of heat loss caused by the heat exchange between air molecules through porous structure of the fiber [27]. This would be a significant advantage of enset fiber compared to other fibers used in sound absorption applications.

\subsection{Acoustic Properties of Enset Fabric and its Composite Structures}

Figure 4 shows sound absorption coefficient of single layer enset fabric backed by polyurethane foam of $6 \mathrm{~mm}$ thickness. The curve below belongs to the polyurethane foam. As seen from the curve, using enset fabric with backing foam increased sound absorption coefficient at all frequencies and it reached around 0.55 at $5500 \mathrm{~Hz}$. A single layer enset fabric with polyurethane foam backing can only absorb the sound waves at high frequency interval with 0.5 sound absorption coefficient. This lower performance of sound absorption can be attributed to open fabric construction of enset fabric.
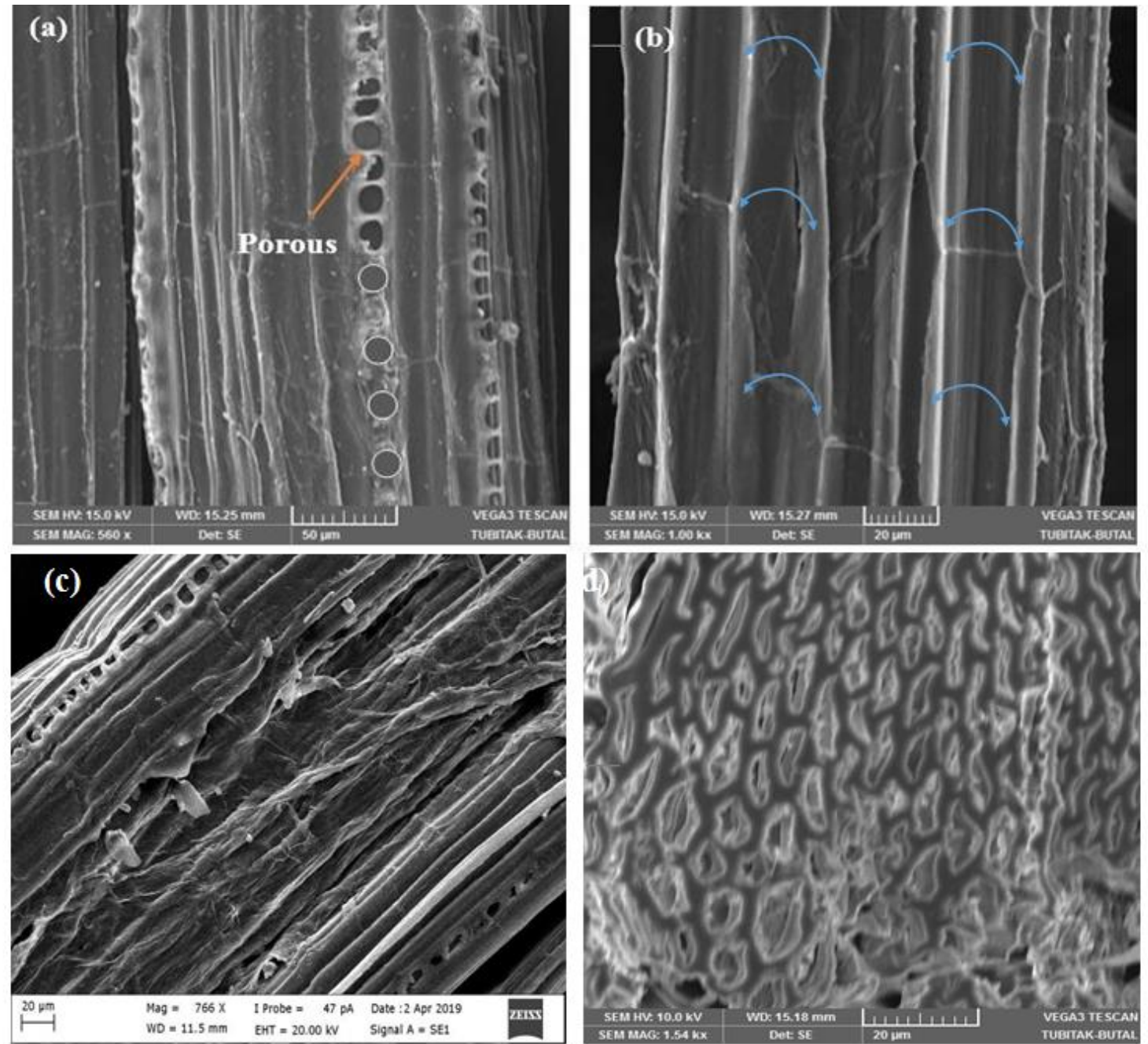

Figure 3. SEM of Enset Fiber (a) Micro Porous structure on the Fiber (b) Longitudinal and Tangential Porous Structure of Enset Fiber (c) Multilayer Void Structure of Enset Fiber (d) Enset Fiber Cross Sectional View. 


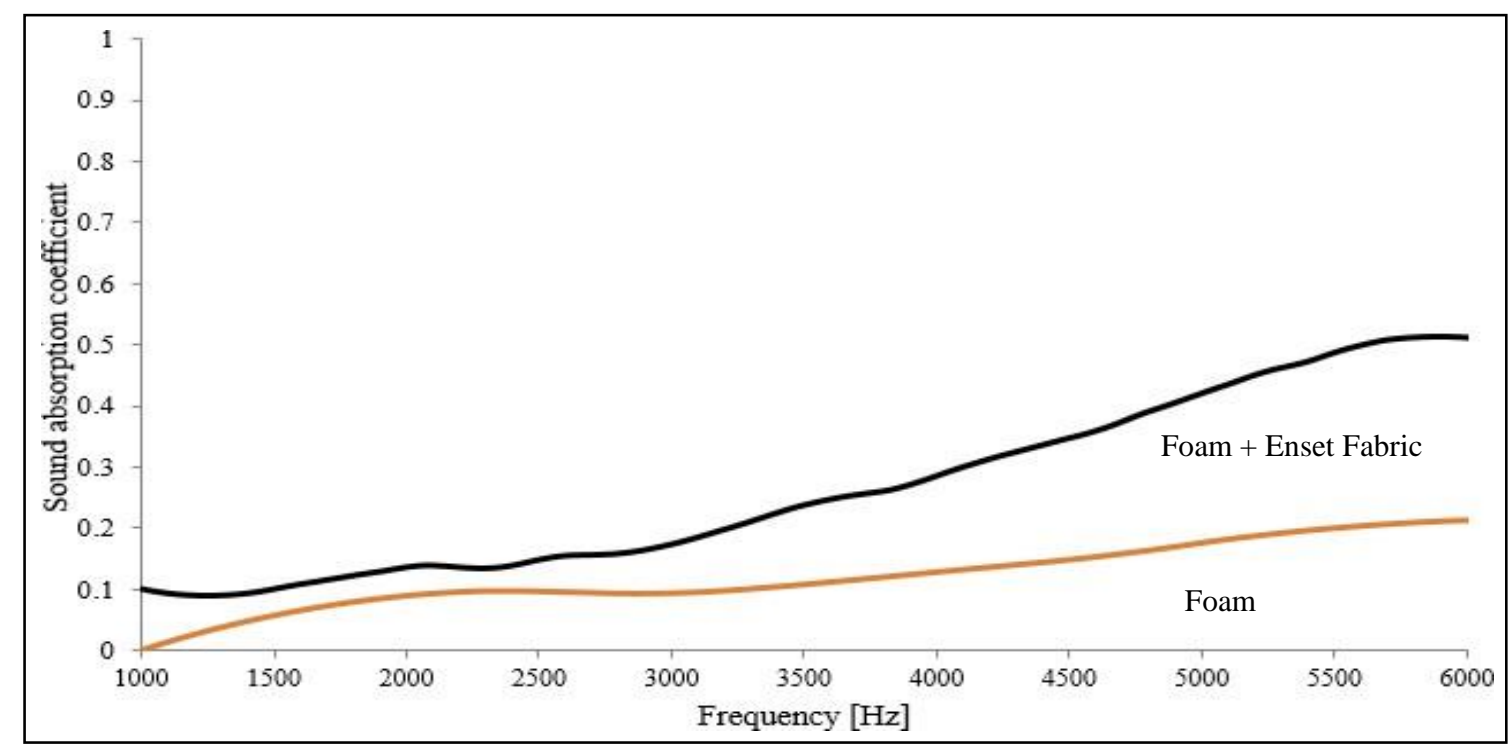

Figure 4. Average Sound Absorption Coefficient of Unidirectional Enset Fabric ( $2 \mathrm{~mm}$ thickness).

Figure 5 shows the sound absorption coefficient change with respect to the sound frequency for single layer enset fabric composite with polyurethane foam backing. As seen from the figure, using enset fabric composite improved sound absorption significantly in comparison to single layer enset fabric and polyurethane foam backing. Composite enset fabric structure not only improved the sound absorption level but also shifted the sound absorption curve to lower frequency range. This absorption mechanism of enset fabric composite can be explained by the structure of the composite. In the enset fabric composite production, hand laying techniques was used and the porosities and voids in the fabric structure were not fully filled by the bio matrix material although the open areas between the yarns were mostly closed. It is thought that the remaining porosity and voids in the composite structure contributed significantly to the sound absorption. The sound absorption coefficient started with near to 0.2 at
$1000 \mathrm{~Hz}$ and tended to increase at a slower rate up to 1500 $\mathrm{Hz}$. It reached to around 0.6 at $2877 \mathrm{~Hz}$ and 0.9 at 3553 Hz. The maximum sound absorption coefficient was obtained as 0.96 around $4100 \mathrm{~Hz}$. Considering Figure 4 and Figure 5 reveals that composite structure of the enset fabric improves sound absorptions significantly in comparison to enset fabric itself. Large porosities and voids in enset fabric can be seen as a reason for this difference. This can be explained by air permeability results presented in Figure 6.

The intra and inter porosity of the fabric highly affects the transportation of air through the composite and enset fabric structure. Analysis of the data in Figure 6 indicates that the air permeability of enset fabric is significantly affected by the structure. The average air permeability of enset fabric was $3046 \mathrm{l} / \mathrm{m}^{2} / \mathrm{sec}$ while it decreased sharply for single and

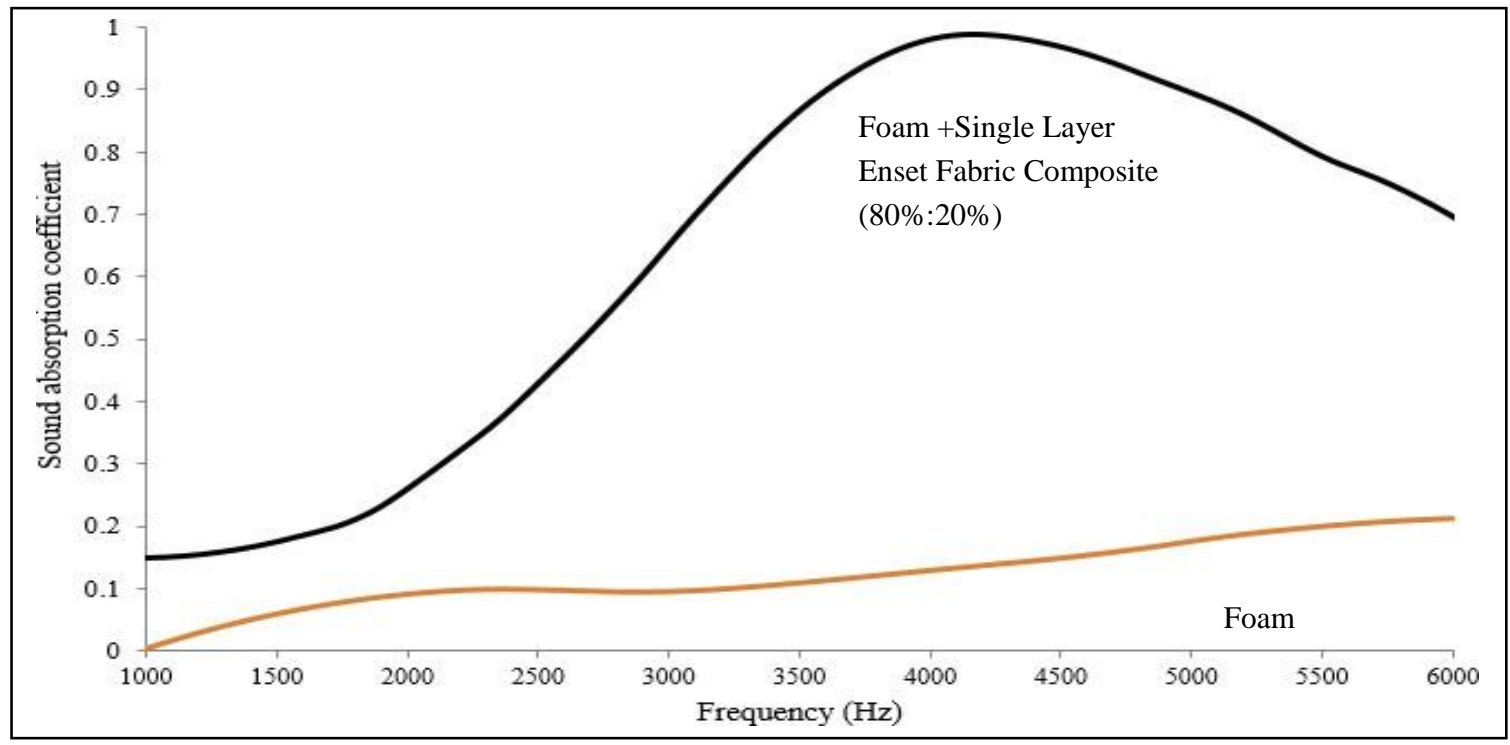

Figure 5. Average Sound Absorption Coefficient of Single Layer Green Composite (2.5 mm thickness). 
double layer enset fabric reinforced composite structure. Single layer and double layer enset fabric reinforced composite structures had air permeability values of 1846 $1 / \mathrm{m}^{2} / \mathrm{sec}$ and $11641 / \mathrm{m}^{2} / \mathrm{sec}$ respectively. These indicate that the porous and void structure of enset fabric was highly affected by the used bio-matrix. Also, the amount of biomatrix on the composite structure had tangible effect on the air permeability characteristics of the composite structure. The air permeability results confirmed that the porosities formed in the composite structure had a significant effect on the acoustic properties by reducing the sound energy due to the friction developed between oscillating air molecules in the pores [28].

\subsection{Effect of Fabric Layer on Acoustic properties of Enset Reinforced Composite Structure}

The effect of number of fabric layer on the sound absorption was investigated by 5 different fabric layer sound absorption measurements. In the measurements, only enset fabrics were used. Polyurethane foam was not included. Number of fabric layers were taken as 1, 2, 3, 4 and 5 in the measurements. The results are shown in Figure 7. As seen from the curves in the figure, the sound absorption coefficient increased very significantly with increasing number of fabric layers. Increase in the sound absorption became more pronounced after $2500 \mathrm{~Hz}$. With single layer fabric, the sound absorption showed only a small increase reaching to 0.1 at $5000 \mathrm{~Hz}$ whereas it became 0.5 at $3500 \mathrm{~Hz}$ and 0.81 at $5000 \mathrm{~Hz}$ with 5 layers enset fabrics. The sound absorption increased at all frequencies as the fabric layer changed from 1 to 5 . But increase in fabric layers increased the sound absorption at the expense of increasing fabric thickness. Five layers in the experimental fabric sample corresponded to around $10 \mathrm{~mm}$, which are equivalent to the thickness of used polyurethane foam. Sound absorption of polyurethane foam plus single layer fabric had a sound absorption coefficient of 0.55 at $5500 \mathrm{~Hz}$ whereas it became 0.69 at the same frequency with four layers of fabrics (have lower thickness). Considering the same thickness of both structures, four layer fabrics became advantageous with higher sound absorption and biodegradable properties compared to using foam. This and large thickness fabrics can be used in applications where there is enough space available.

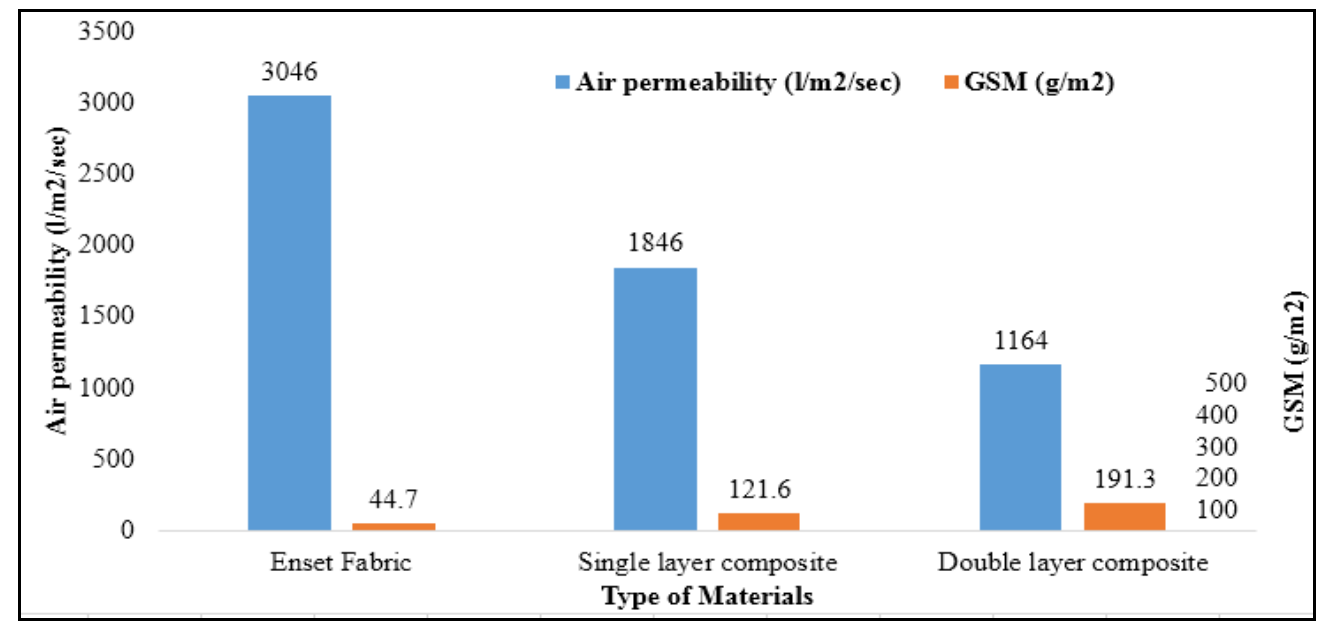

Figure 6. Air Permeability of Enset Fabric and Its Green Composite.

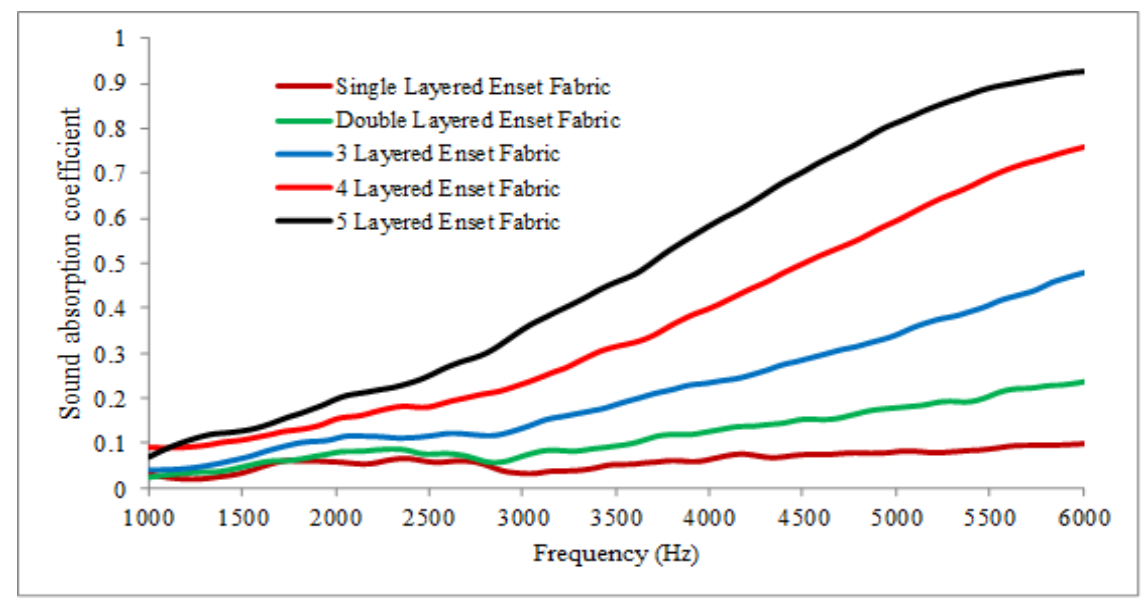

Figure 7. Effect of Enset Fabric Number of Layers on Sound Absorption Properties. 
To investigate the sound absorption properties of multilayer composite structures, the measurements were conducted by using 2, 3, 4 and 5 layer composite samples without polyurethane foam. Composite samples were produced with 70:30 wt. \% resin to enset fabric weight ratio. The results are presented with respect to sound wave frequency in Figure 8. The sound absorption curves with composite structures differed from sound absorption curves of multilayer fabrics (see in Figure 7) in that the maximum absorption values were reached at lower frequencies with composites. The maximum sound absorption was obtained at around $4100 \mathrm{~Hz}$ as 0.95 with five layers (around $10 \mathrm{~mm}$ thickness) while it reached at $5000 \mathrm{~Hz}$ to 0.95 with four layer samples. For two and three layers, the sound absorption coefficients were measured as 0.34 and 0.83 respectively at $6000 \mathrm{~Hz}$. With five layers composite, a sound absorption coefficient remained over 0.5 at large frequency interval between 2830 and $6000 \mathrm{~Hz}$. This result can be attributed to fibrous and porous structure of enset fabric reinforced composite. A similar trend was observed in sound absorption curve of four layers composite. The results in Figure 8 suggest that the sound absorption frequency interval can be shifted to lower frequency range by increasing number of layer in enset fabric bio-composite.

\subsection{Effect of Bio Matrix Weight Ratio on Acoustic Performance of Green Composite}

Because of the variation of bio matrix weight ratios, a significant sound absorption performance change was obtained in enset fabric reinforced bio-composite. It was decided to further investigate the effect of matrix weight ratio on acoustic performance of the composite. For this purpose, the composites were produced with 80:20 wt. \% and 70:30 wt \% resin to enset fabric ratio and sound absorption measurements were performed with 2, 3, 4 and 5 layers of composites without polyurethane foam. The results are presented in Figure 9. Putting Figure 7, 8 and 9 side by side shows a very explanatory change about the effect of bio matrix material on sound absorption behavior. Without bio matrix material, the sound absorption of neat enset fabrics increased with increasing number of layers at high frequency range towards $6000 \mathrm{~Hz}$ (Figure 7). In all layers the sound absorption coefficient continuously increased up to $6000 \mathrm{~Hz}$. As seen from Figure 8, when the enset fabric was converted to composite structure with 70:30 wt. \% resin to enset fabric weight ratio, the sound absorption shifted to lower and medium frequency range with higher absorption coefficients. Increasing bio matrix ratio in composite structure to $80: 20 \mathrm{wt}$. \% resin to enset fabric weight ratio produced a significant improvement in sound absorption. According to Figure 9, the sound absorption curves shifted towards lower frequency range. The sound absorption interval between 0.5 and 0.95 corresponded to lower frequency interval between 1800 and $4000 \mathrm{~Hz}$ for five layer fabrics in the composite structure. This interval became narrower compared to 70:30 wt. \% weight ratio for the same number of layer. Result of four layer composites also indicated a similar trend. This is thought to be due to partly shift of the composite structure from fibrous and porous nature to more solid structure with increasing matrix weight ratio.

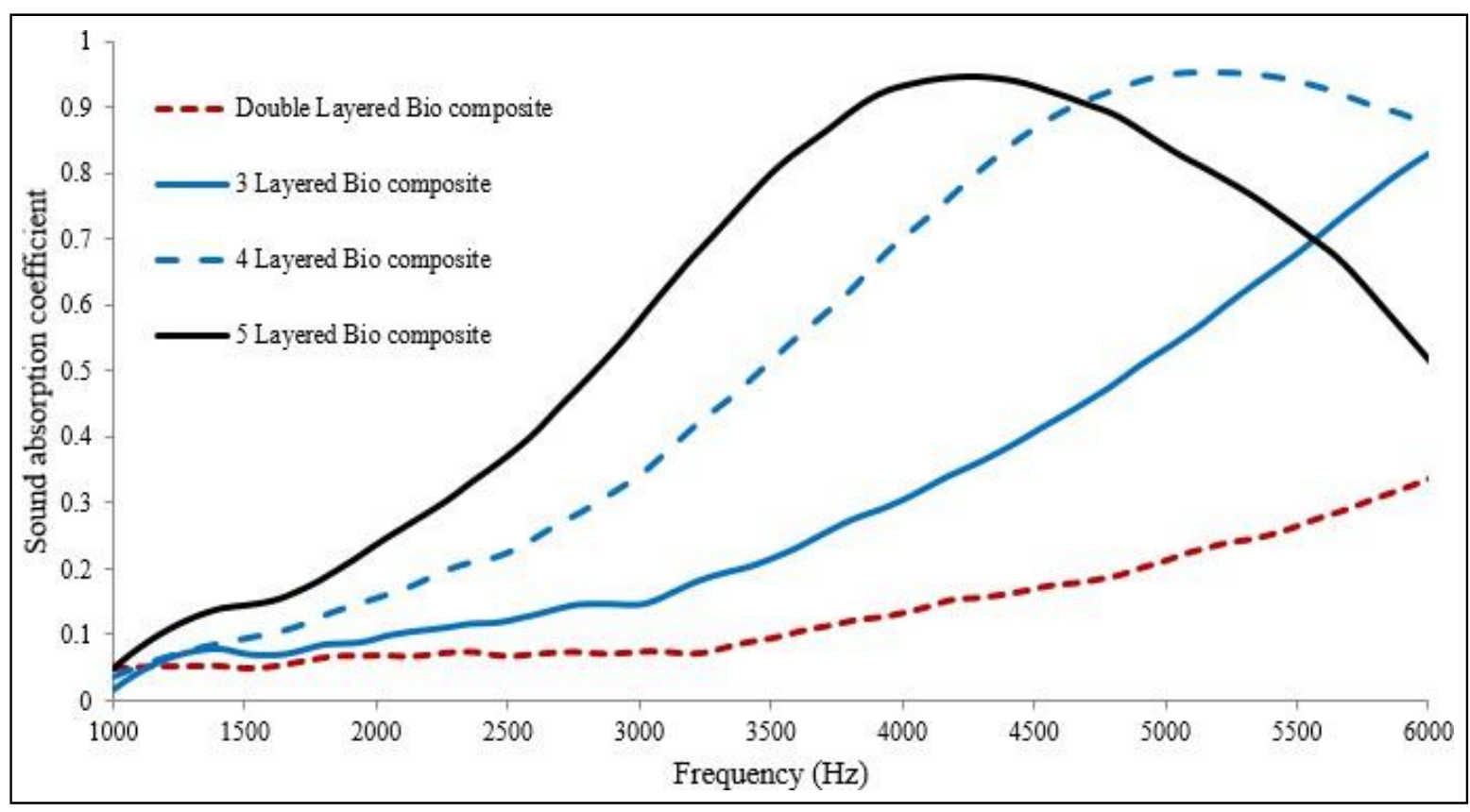

Figure 8. Effect of Green Composite Layering on Peak Shifting of Sound Absorption Region. 


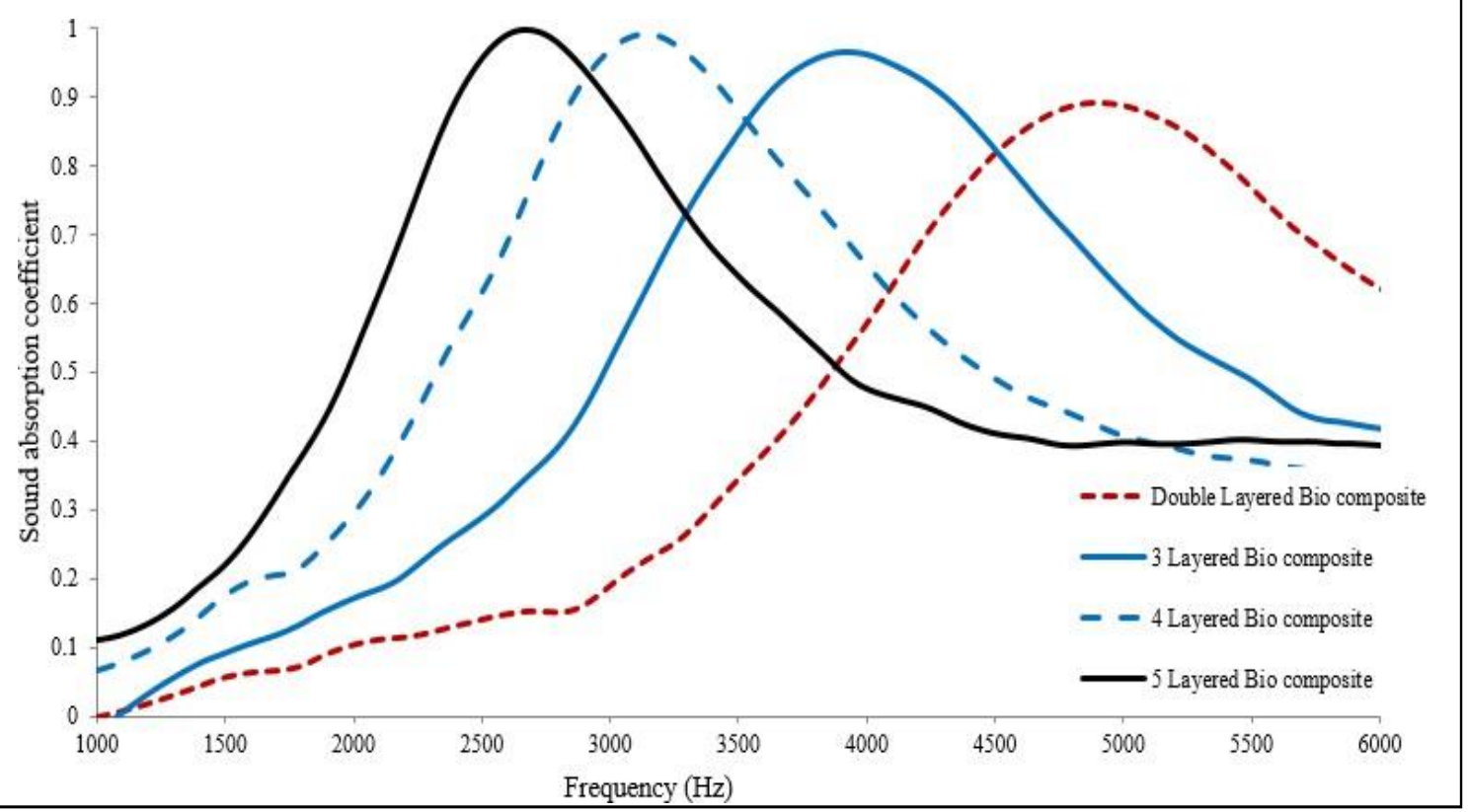

Figure 9: Sound Absorption Coefficient of Enset Fabric Reinforced Composite with 80:20 Wt. \% Bio Matrix -Fiber Combination.

\section{CONCLUSION}

The following conclusion can be drawn from the above explained research.

- -This research focused on the possibility of using enset fiber based fabric, which is an agro waste product and abundantly available and low cost, in sound absorption applications.

- Morphological examination of enset fiber with scanning electron microscope revealed that the fiber had highly porous and void structures, which were expected to influence the sound absorption performance.

- -The sound absorption results showed that multilayer enset fabric produced higher sound absorption coefficient compared to polyurethane foam of the same thickness. This is thought to be an advantage as enset fabric is fully green materials.

- -It was shown by the research results that composite material produced from enset fabric improved sound absorption properties compared to only enset fabric without bio-matrix material.
- -It was also shown that the sound absorption behavior of multilayer composite structure could be enhanced and shaped by changing matrix materials weight ratio.

- A better sound absorption results could be expected from specially designed multilayer enset fabric constructions and their composites with optimum porous and void structure. This will enable an agro waste enset fiber to be used in sound absorption applications with a biodegradable properties.

\section{Acknowledgement}

This research work was a part of Alhayat Getu TEMESGEN's $\mathrm{PhD}$ Thesis doing in Bursa Uludag University, Graduate School of Natural and Applied Sciences, Department of Textile Engineering. The authors gratefully acknowledge and express our sincere thanks Wollo University, Ömer Fırat TURŞUCULAR and Abdulkarim Yahya AWOL supporting in laboratory during the study and Mehmet TİRITOĞLU for his supporting and allowing to use all the necessary laboratory equipment's for this study. 


\section{REFERENCES}

1. Müller G, Möser M. 2017. Engineering Acoustics, Sound Absorbing Structures and Materials. Sprinfger, NewYork,

2. Chen D., Li J. and Ren J.2010. Study on sound absorption property of ramie fiber reinforced poly (l-lactic acid) composites: Morphology and properties. Composites Part A: Applied Science and Manufacturing 41(8), 1012-1018.

3. Ismail L., Ghazali M.I., Mahzan S. and Zaidi A.A. 2010. Sound absorption of Arenga Pinnata natural fiber. World Academy of Science, Engineering and Technology 67, 804-806.

4. Zunaidi N.H., Tan W.H., Majid M.S.A. and Lim E.A. 2017, October. Effect of physical properties of natural fibre on the sound absorption coefficient. In Journal of Physics: Conference Series Vol. 908, No. 1, 012023. IOP Publishing.

5. Ekici B., Kentli A. and Küçük H. 2012. Improving sound absorption property of polyurethane foams by adding tea-leaf fibers. Archives of Acoustics 37, 515-520.

6. Mamtaz H., Fouladi M.H., Al-Atabi M. and Namasivayam S. 2016. Acoustic absorption of natural fiber composites. Journal of Engineering, 1-6. http://dx.doi.org/10.1155/2016/5836107

7. Joshi S.V., Drzal L.T., Mohanty A.K. and Arora S. 2004. Are natural fiber composites environmentally superior to glass fiber reinforced composites. Composites Part A: Applied science and manufacturing 35(3), 371-376.

8. Zhang J., Shen Y., Jiang B. and Li Y. 2018. Sound absorption characterization of natural materials and sandwich structure composites. Aerospace 5(3), 75. doi: 10.3390/aerospace5030075.

9. Lee H.P., Ng B.M.P., Rammohan A.V. and Tran L.Q.N. 2017. An investigation of the sound absorption properties of flax/epoxy composites compared with glass/epoxy composites. Journal of Natural Fibers 14(1), 71-77.

10. Ogulata R.T. 2006. Air permeability of woven fabrics. Journal of Textile and Apparel, Technology and management 5(2), 1-9.

11. Mohanty A.R. and Fatima S. 2015. Noise control using green materials. Sound and Vibration 49(2), 13-15.www.SandV.com

12. Reddy N. and Yang Y. 2011. Novel green composites using zein as matrix and jute fibers as reinforcement. Biomass and bioenergy 35(8), 3469-3503

13. Tholkappiyan E., Saravanan D., Jagasthitha R., Angeswari T. and Surya V.T. 2016. Prediction of acoustic performance of banana fiber-reinforced recycled paper pulp composites. Journal of Industrial textiles 45(6), 1350-1363.

14. Cao L., Fu Q., Si Y., Ding B. and Yu J. 2018. Porous materials for sound absorption. Composites Communications 10, 25-35.
15. Berardi U., Iannace G.2015. Acoustic characterization of natural fibers for sound absorption applications. Build. Envirn 94, 840-852.

16. Jayamani E., Hamdan S., Ezhumalai P. and Bakri M.K. 2016. Investigation on dielectric and sound absorption properties of banana fibers reinforced epoxy composites. Jurnal Teknologi, 78(6-10).

17. Chen S.M., Jiang Y., Chen-Wang J. 2015. The effects of various additive components on the sound absorption performances of polyurethane foams. Adv. Mater. Sci. Eng. 31, 61-75.

18. Arenas J.P., Crocker M.J.2010. Recent trends in porous soundabsorbing materials. Sound Vib. 44, 12-17.

19. Soltani P. and Zarrebini M. 2013. Acoustic performance of woven fabrics in relation to structural parameters and air permeability. Journal of the Textile Institute 104(9), 1011-1016.

20. Tang X., Jeong C.H. and Yan X. 2018. Prediction of sound absorption based on specific airflow resistance and air permeability of textiles. The Journal of the Acoustical Society of America 144(2), 100-104.

21. Yang Y., Li B., Chen Z., Sui N., Chen Z., Saeed M.U., Li Y., Fu R., Wu C. and Jing Y. 2016. Acoustic properties of glass fiber assemblyfilled honeycomb sandwich panels. Composites Part B: Engineering 96, 281-286.

22. Gwon J.G., Kim S.K., Kim J.H. 2016. Sound absorption behavior of flexible polyurethane foams with distinct cellular structures. Mater. Des. 89, 448-454.

23. Bratu M., Ropota I., Vasile O., Dumitrescu O. and Muntean M 2011. Sound-absorbing properties of composite materials reinforced with various wastes. Environmental Engineering and Management Journal 10(8), 1047-1051.

24. Cobo P., De Espinosa F.M. 2013. Proposal of cheap microperforated panel absorbers manufactured by infiltration. Appl. Acoust 74, 1069 1075 .

25. Temesgen A.G., Sahu O. 2014. Process Ability Enhancement of False Banana Fiber for Rural Development. Journal of Agricultural Economics, Extension and Rural Development 1, 63-73.

26. 25. Temesgen A.G., Sahu O. 20142. Green composite material from agricultural waste. International Journal of Agricultural Research and Reviews 5,56-62.

27. Singh V.K. and Mukhopadhyay S. 2020. Banana fibre-based structures for acoustic insulation and absorption. Journal of Industrial Textiles $0(0), 1-2$

28. Suvari F., Ulcay Y. and Pourdeyhimi B. 2016. Sound absorption analysis of thermally bonded high-loft nonwovens. Textile Research Journal 86(8), 837-847. 